1 College of Social Sciences, University of Glasgow, Glasgow, UK

2 Usher Institute, College of Medicine and Veterinary Medicine, University of Edinburgh, Edinburgh, UK

3 Public Health Scotland, Glasgow, UK

4 MRC/CSO Social and Public Health Sciences Unit, University of Glasgow, Glasgow, UK

5 Department of Health Services Research and Policy, London School of Hygiene and Tropical Medicine, London, UK

Correspondence to: G McCartney Gerard.McCartney@glasgow.ac.uk Cite this as: BMJ 2021;375:e066232 http://dx.doi.org/10.1136/bmi-2021-066232 Published: 7 December 2021

\section{Tackling population health challenges as we build back from the pandemic}

\section{Gerry McCartney and colleagues argue for a new model of equitable, holistic, and sustainable public health should be central to recovery plans}

Gerry McCartney, ${ }^{1,3}$ Margaret Douglas, ${ }^{2,3}$ Martin Taulbut, ${ }^{3}$ S Vittal Katikireddi, ${ }^{3,4}$ Martin McKee ${ }^{5}$

http://dx.doi.org/10.13039/501100000589

Chief Scientist Office

http://dx.doi.org/10.13039/501100000265

Medical Research Council

No amount of positive spin can detract from the numbers. The UK has not done well in the pandemic, whether measured in terms of mortality, ${ }^{1}$ economic performance, ${ }^{2}$ or social protection. This should not have happened. In 2019, the UK came in second place in the Global Health Security Index. ${ }^{3}$ Yet, when the pandemic arrived, decision making was confused and slow, ${ }^{4}$ existing structures were sidelined, and new ones, exemplified by the "eye wateringly expensive" test and trace system, ${ }^{5}$ were flawed by design, paying inadequate attention to the needs of those isolating. ${ }^{6}$ Weak social safety nets offered little support. $^{7}$

Other countries also struggled, but the UK was especially vulnerable as the pandemic exposed deep societal and health problems that had been neglected for years (fig 1). ${ }^{8}{ }^{9}$ In marked contrast to many other high income countries, ${ }^{10}$ the UK's long term upward trend in life expectancy stalled after 2012. ${ }^{11}$ Existing inequalities in mortality had widened, ${ }^{12}$ and death rates among working age adults had been rising in some places, with drug related deaths a major factor, ${ }^{13}$ mirroring trends in the US. ${ }^{14}$ Here we set out three key population health challenges that the UK must now tackle and embed in government strategy.

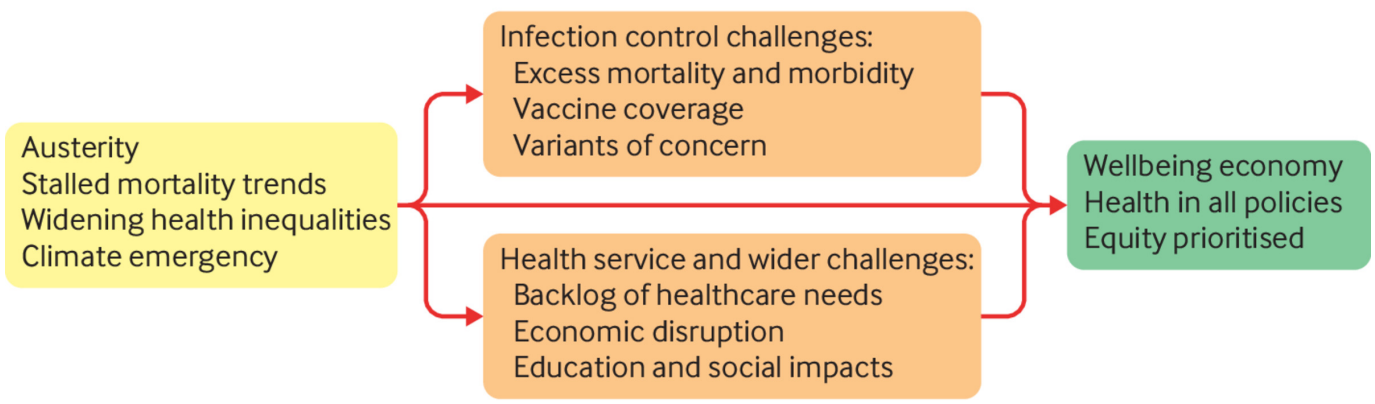

Wider policy challenges (present pre-pandemic)<smiles>[CH]1[CH]CC1</smiles>

Radical, strategic, long term policy shift to improve population health and reduce health inequalities in sustainable and equitable manner

Infection control and health service challenges (pandemic)

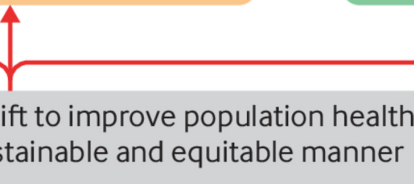

Fig 1 | The inter-related challenges from before, during, and after the pandemic

\section{Pressing population health challenges Ongoing infection control}

First, we are not yet out of the woods with the pandemic and cannot depend on vaccines alone to beat it. The combination of many adults still being unvaccinated (especially globally), incoherent messaging on childhood vaccination, and waning immunity, risks the emergence of vaccine resistant variants. The UK lacks a comprehensive control strategy for the long term. ${ }^{15}{ }^{16}$ It needs an effective contract tracing system and vaccination strategy, built on increased investment in local in-sourced public health systems as well as sufficient financial support for people to isolate, improved ventilation of buildings, more home working, and consistent encouragement of mask wearing. 


\section{Strained health services}

The NHS saw a steep decline in use of many non-urgent services in the initial wave of the pandemic, ${ }^{17}$ partly because of reduced need but also because of reduced service supply and postponement of public demands on services. For example, counts of confirmed cancer diagnoses in Scotland dropped by around half in the first months of "lockdown" before slowly recovering to close to 2019 levels (fig 2), with 16\% fewer diagnoses made during 2020 than in 2019. Cancer incidence cannot have changed so quickly, and this therefore represents substantial unmet need in the system.

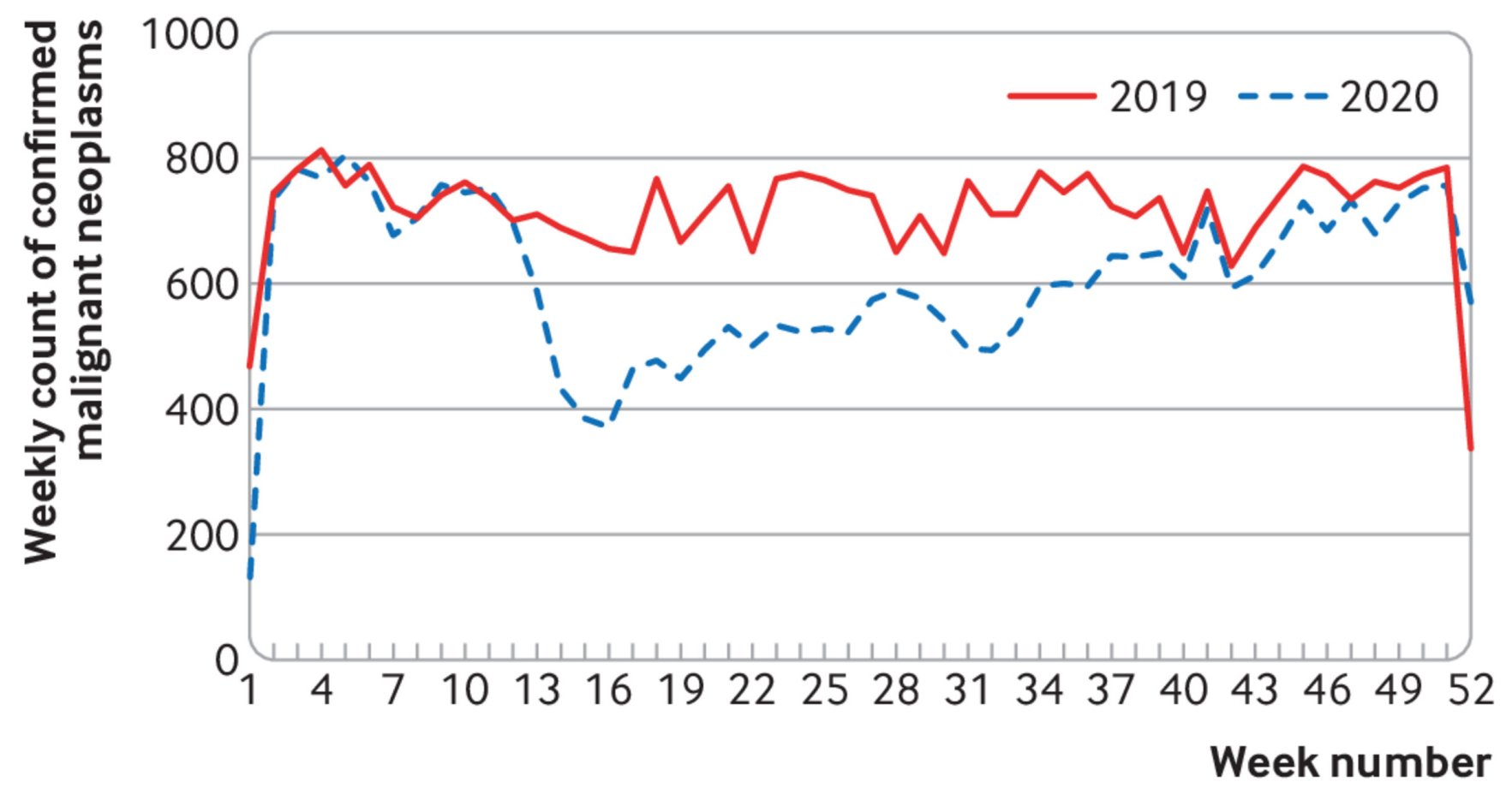

Fig 2 | Trends in confirmed cancer diagnoses in Scotland ${ }^{18}$ (all malignant neoplasms, excluding non-melanoma skin cancers) confirmed with a pathological specimen, 2019-2020

Health services-delivered by an exhausted and depleted workforce-face increased waiting lists and the consequences of delayed care, additional needs driven by lockdown experiences (eg, increased mental ill health and obesity), continuing covid-19 cases, and the burden of long covid. Physical distancing requirements and the use of personal protective equipment (PPE) place additional strain on healthcare workers, who already had high levels of work related stress before the pandemic. ${ }^{19}$ The social care system needs radical reform, professionalisation, and increased funding to provide sufficient levels of quality care. ${ }^{20}$ Although more resources have now been committed to the NHS and social care, further increases are likely to be needed to prevent avoidable morbidity and mortality.

\section{Wider policy challenges}

Women, young people, disabled adults, and ethnic minorities ${ }^{21}$ have disproportionately borne the economic and social brunt of the pandemic. Young people, especially those already disadvantaged, may struggle to make up for lost opportunities for education and social development, and these are likely to have lifelong consequences for health. ${ }^{22}$ Although massive state intervention, including the furlough scheme, has avoided some of the mistakes of the financial crisis and increased prospects for a rapid economic recovery, many people have not benefitted. Withdrawal of the temporary increase in financial support through universal credit, coupled with continuation of pre-crisis policies to cut social protection (eg, the two child limit and benefits cap), is a particular risk when many families cannot compensate for these losses by increasing earned income.
The reversal of policies aimed at narrowing inequalities together with other factors, including neoliberal economic policies such as austerity, Brexit, increases in the power of the executive (such as curbs on judicial review), a failure to tackle racism (exemplified by the heavily criticised report of the Commission on Race and Ethnic Disparities), ${ }^{23}$ and repeated breaches of parliamentary standards, point to widespread governance failures. ${ }^{24}$ These will make change more difficult.

Perhaps the biggest policy challenge affecting health is the threat from climate change. ${ }^{25}$ At the root of climate change is the design of the global economy, driven by consumption in high income countries, and fundamental change is needed to achieve rapid and extensive reductions in greenhouse gas emissions.

\section{Building the recovery}

These complex and inter-related health challenges require a strategic, long term, and radical response that tackles the wider challenges of economic inequality and climate change (fig 1).

Health policy responses to the pandemic have often been reactive and driven by the need to reduce viral transmission, with less consideration of interactions with social and economic factors and the longer term consequences of measures taken. This has widened inequalities attributable to both direct and indirect effects of the pandemic. ${ }^{21}$ Yet continued threats to health are not inevitable. ${ }^{26}$ Politicians have choices. And it is reasonable to call on them to ensure that these choices pay particular attention to those with low incomes, insecure employment, and cramped housing conditions 
who have been disproportionately affected during the pandemic. Countries that have prepared for future threats and acted rapidly and decisively when they arise have fared better, safeguarding the health of their people and of their economies, core roles of government, while those that fail to do so will be judged adversely by history (and, likely, their electorates). We argue that three linked approaches are needed to protect health in the aftermath of the pandemic.

\section{Prioritise equity}

Recovery planning must prioritise investment in the wellbeing of populations (especially low income families, caregivers, and people with disabilities) that have been most severely affected by the pandemic. ${ }^{21}$ Financial, practical, and educational support for children and families will be required to reverse widening inequalities. In doing so, it is important to learn from policies that have gone before such as: Sure Start centres, which have been show to reduce hospital admissions; child tax credit expansion in the US, which has reduced food insecurity ${ }^{27}$; and learning from the $2000 \mathrm{~s}$ when child and pensioner poverty fell in Britain, "overwhelmingly driven by tax and benefit policies, and large increases in welfare entitlements." 28

Policies introduced during the pandemic like the "Everyone In" policy, which offered shelter to or all rough sleepers in the first lockdown, and the increase in universal credit while reducing conditionality to reduce poverty rates show what is possible to protect vulnerable populations. Like the state pension and the NHS, these policies and approaches should become routine in the British welfare state.

In addressing the backlog of unmet healthcare need, more of the additional investment in health needs to go to primary care and social care. Such investment has long been recognised as necessary to enhance prevention, reduce demand, and reduce inequalities in access to services. ${ }^{29-31}$ This is even more important for a health service that is experiencing the combined effects of an ageing population, the continued growth of unmet need throughout the pandemic, disruption due to Brexit, and, in England, a major service reorganisation.

\section{Adopt a "health in all policies" approach}

As we move towards the recovery phase it will be essential to ensure that all policies (housing, employment, energy, social security, transport, justice, etc), not just healthcare help promote health and reduce health inequalities. This is called a "health in all policies" approach $^{32}$ and involves public health professionals working closely with policy makers and others in public, private, and third sector institutions, at different geographical levels, to influence policy and tackle the wider social determinants of health. Well established processes like health impact assessment provide a practical way to do this. 33

Public Health Scotland took this approach in its social and system recovery programme, set up to respond to the wider effects of the pandemic. ${ }^{21}$ An example is work with transport policy makers and planners that recommended policies to the Scottish government, local government, and other transport providers to improve health and sustainability during lockdown and beyond. This included policies to maintain the provision of public transport and improve infrastructure for walking and cycling. ${ }^{34}$ Similar analyses seeking to reduce the adverse economic impacts of the pandemic identified a series of policies that could be implemented to reduce poverty, increase employment inclusivity, and redesign the economy to reduce inequalities. ${ }^{35}$ These recognised the key role of the economy in modifying the effect of the pandemic on health (eg, by reducing inequalities in exposure and susceptibility to the direct and indirect pandemic impacts ${ }^{36}$ ) and the consequences thereof, and its importance for long term health trends. ${ }^{12}$

\section{Create a new economic model}

The third element is more fundamental and requires radical change. Addressing the fractures in our society illuminated by the pandemic requires a different economic model from the one that created many of the health problems discussed above. It requires economic institutions and governance mechanisms designed explicitly to provide equitable distribution of benefits and resources, within planetary boundaries. ${ }^{37}$ Some governments and other institutions are already collaborating on ways to create "wellbeing economies" that prioritise human and ecological wellbeing above economic growth. ${ }^{38}$ Economies redesigned in this way would have low inequality and poverty; would rapidly reduce greenhouse gas emissions and excessive consumption; and would create space, time, and work that is fulfilling and contributes to social outcomes.

Global inequalities in covid-19 vaccination have shown the need for global cooperation to shift towards a wellbeing economy. For example, vaccine supplies have not been produced or distributed globally according to need; costs and a lack of healthcare infrastructure have been substantial barriers; and lack of trust in institutions has damaged confidence in vaccine safety. Furthermore, by reducing the demands on healthcare and other services by reducing poverty, environmental damage, and all of the negative "side effects" of the current economic model, 39 a new model can go a long way to addressing the long term financial challenges facing governments. We need to identify, investigate, and evaluate alternative economic models and ensure that the risks, benefits, and uncertainties of all future scenarios are well understood by policy makers and the public. ${ }^{40}$

\section{Conclusion}

An appropriate policy response to today's challenges needs to radically reduce economic and social inequality, protect incomes, and reduce poverty, provide sufficient resources for the health and social care system, and do all of this within planetary boundaries. This level of change may have seemed unthinkable two years ago, but the pandemic has taught us that governments can act quickly and radically when required. The pandemic has highlighted the cost of prioritising the short term interests of better-off adults over the long term health and wellbeing of the population as a whole. Rebalancing requires a fundamental shift in the purpose and design of the economy. Given the scale of the challenges facing us, a new framework of holistic, equitable, and sustainable public health is urgently needed.

\section{Key messages}

- A decade of austerity, stalled mortality trends, widening health inequalities, and climate change present profound health challenges that predate the pandemic

- The pandemic has shown that population health in the UK is insecure

- It has created additional challenges from ongoing covid-19, unmet health and social care needs, and social and economic disruption

- A radical shift in the government's approach to population health is needed, integrating equity and health in all policies, and shifting to a wellbeing economy

SVK acknowledges funding from a NRS senior clinical fellowship (SCAF/15/02), the Medical Research Council (MC_UU_00022/2), and Scottish Government Chief Scientist Office (SPHSU17). 
Contributors and sources: The authors collaborated on a rapid health impact assessment on the unintended impacts of social distancing measures published during the first wave of the covid-19 pandemic. All authors have contributed widely to the literature on the population health challenges listed in this article. The idea for this paper came through discussion between GM, MD, SVK, MT and MMcK. GM drafted the manuscript and all authors made substantial contributions of intellectual content and edits, and approved the final draft. GM is guarantor. The views expressed here do not necessarily represent the views of the employing organisations.

Competing interests: We have read and understood BMJ policy on declaration of interests and declare that MMcK is a member of Independent SAGE and SVK was co-chair of the Scottish Government's expert reference group on ethnicity and covid-19 and a member of the Scientific Advisory Group on Emergencies (SAGE) subgroup on ethnicity.

\section{Provenance and peer review: Not commissioned; externally peer reviewed.}

1 Islam N, Jdanov DA, Shkolnikov VM, etal. Effects of covid-19 pandemic on life expectancy and premature mortality in 2020: time series analysis in 37 countries. BMJ 2021;375:e066768. doi: 10.1136/bmj-2021-066768 pmid: 34732390

2 ONS. International comparisons of GDP during the coronavirus (COVID-19) pandemic. 2021. https://www.ons.gov.uk/economy/grossdomesticproductgdp/articles/internationalcomparisonsofgdpduringthecoronaviruscovid19pandemic/2021-02-01

3 Cameron EE, Nuzzo JB, Bell JA, et al. Global Health Security Index: building collective action and accountability. 2019. https://www.ghsindex.org/

4 UK Health and Social Care, and Science and Technology Committees Coronavirus: lessons learned to date. 2021, https://publications.parliament.uk/pa/cm5802/cmselect/cmsctech/92/9203.htm

5 House of Commons Committee of Public Accounts. Test and trace update. 2021. https://committees.parliament.uk/publications/7651/documents/79945/default/

6 Smith LE, Potts HWW, Amlôt R, Fear NT, Michie S, Rubin G). Adherence to the test, trace, and isolate system in the UK: results from 37 nationally representative surveys. BM/2021;372:n608. doi: 10.1136/bmj.n608 pmid: 33789843

7 Cooper K, Hills J. The Conservative governments' record on social security: policies, spending and outcomes, May 2015 to pre-COVID 2020. SPDO research paper. 2021. https://sticerd.lse.ac.uk/CASE/_new/publications/abstract/?index=7765

8 Hiam L, Dorling D, McKee M. Things fall apart: the British health crisis, 2010-2020. Br Med Bull 2020;133:4-15. doi: 10.1093/bmb/ldz041 pmid: 32219417

9 Katikireddi SV, Hainey KJ, Beale S. The impact of COVID-19 on different population subgroups: ethnic, gender and age-related disadvantage. J R Coll Physicians Edinb 2021;51(S1):S40-6. doi: 10.4997/JRCPE.2021.240 pmid: 34185037

10 Fenton L, Minton J, Ramsay J, etal. Recent adverse mortality trends in Scotland: comparison with other high-income countries. BMJ Open 2019;9:e029936. doi: 10.1136/bmjopen-2019-029936 pmid: 31676648

11 Minton J, Fletcher E, Ramsay J, Little K, McCartney G. How bad are life expectancy trends across the UK, and what would it take to get back to previous trends?] Epidemiol Community Health 2020;74:741-6. doi: 10.1136/jech-2020-213870 pmid: 32385127

12 Marmot M, Allen J, Goldblatt P, Herd E, Morrison J. Build back fairer: the covid-19 Marmot review. 2020. https://www.health.org.uk/publications/build-back-fairer-the-covid-19-marmot-review

13 Walsh D, McCartney G, Minton J, Parkinson J, Shipton D, Whyte B. Changing mortality trends in countries and cities of the UK: a population-based trend analysis. BMJ Open 2020;10:e038135. doi: 10.1136/bmjopen-2020-038135 pmid: 33154048

14 Glei DA, Preston SH. Estimating the impact of drug use on US mortality, 1999-2016. PLoS One 2020;15:e0226732. doi: 10.1371/journal.pone.0226732 pmid: 31940370

15 Baker MG, Wilson N, Blakely T. Elimination could be the optimal response strategy for covid-19 and other emerging pandemic diseases. BMJ 2020;371:m4907. doi: 10.1136/bmj.m4907 pmid: 33561814

16 Sheikh A, Sheikh A, Sheikh Z, Dhami S, Sridhar D. What's the way out? Potential exit strategies from the COVID-19 lockdown. J Glob Health 2020;10:010370. doi: 10.7189/jogh.10.010370 pmid: 32566161

17 Di Gessa G, Maddock J, Green MJ, etal. Mental health inequalities in healthcare, economic, and housing disruption during COVID-19: an investigation in 12 longitudinal studies.medRxiv 2021:2021.04.01.21254765

18 COVID-19 wider impacts on the health care system. Edinburgh, Public Health Scotland, 2021. https://scotland.shinyapps.io/phs-covid-wider-impact/

19 Green F, Felstead A, Gallie D, Henseke, G. Work intensity in Britain - first findings from the skills and employment survey 2017. Centre for Learning and Life Chances in Knowledge Economies and Societies, UCL Institute of Education, 2018.

20 Rajan S, Comas-Herrera A, McKee M. Did the UK government really throw a protective ring around care homes in the COVID-19 pandemic?J Long-Term Care 2020;2020:185-95doi: 10.31389/jltc.53

21 Suleman M, Sonthalia S, Webb C, et al. Unequal pandemic, fairer recovery. Health Foundation, 2021, https://www.health.org.uk/publications/reports/unequal-pandemic-fairer-recovery

22 Douglas M, Katikireddi SV, Taulbut M, McKee M, McCartney G. Mitigating the wider health effects of covid-19 pandemic response. BM/2020;369:m1557. doi: 10.1136/bmj.m1557 pmid: 32341002

23 Commission on Race and Ethnic Disparities. The Report. Commission on Race and Ethnic Disparities, 2021. https://assets.publishing.service.gov.uk/government/uploads/system/uploads/attachment_data/file/974507/20210331___CRED_Report___FINAL_-_Web_Accessible.pdf
24 Calvert J, Arbuthnott G. Failures of state: the inside story of Britain's battle with coronavirus. Harper Collins, 2021.

25 Intergovernmental Panel on Climate Change. Synthesis report of the sixth assessment report. 2021. https://www.ipcc.ch/assessment-report/ar6/

26 McCartney G, Hearty W, Arnot J, Popham F, Cumbers A, McMaster R. Impact of political economy on population health: a systematic review of reviews. Am J Public Health 2019;109:e1-12. doi: 10.2105/AJPH.2019.305001 pmid: 31067117

27 Parolin Z, Ananat E, Collyer SM, Curran M, Wimer C. The initial effects of the expanded child tax credit on material hardship. NBER, 2021, https://www.nber.org/papers/w29285

28 Joyce R, Sibieta L. An assessment of Labour's record on income inequality and poverty. Oxf Rev Econ Policy 2013;29:178-202doi: 10.1093/oxrep/grt008

29 Wanless D. Securing good care for older people: taking a long-term view. King's Fund, 2006, https://www.kingsfund.org.uk/publications/securing-good-care-older-people

30 Mercer SW, Patterson J, Robson JP, Smith SM, Walton E, Watt G. The inverse care law and the potential of primary care in deprived areas. Lancet 2021;397:775-6. doi: 10.1016/S0140-6736(21)00317-2 pmid: 33640047

31 Scottish Government. Christie Commission on the future delivery of public services. 2011. https://www.gov.scot/publications/commission-future-delivery-public-services/

32 WHO Adelaide Statement on Health in All Policies. 2010. https://www.who.int/social_determinants/publications/isa/hiap_statement_who_sa_final.pdf?ua=1

33 Green L, Ashton K, Bellis MA, Clemens T, Douglas M. Health in all policies - a key driver for health and well-being in a post covid-19 pandemic world. Int J Environ Res Public Health 2021;18:9468. . doi: 10.3390/ijerph18189468 pmid: 34574390

34 Teuton J, Sloan P, Whyte B, et al. Transport use, health and health inequalities: the impact of measures to reduce the spread of COVID-19. A rapid review of evidence in support of a health inequalities impact assessment. Edinburgh: Public Health Scotland. 2020. https://publichealthscotland.scot/media/2850/transport-use-health-and-health-inequalities-oct2020-english.pdf

35 Burnett D, Katikireddi SV, Kromydas T, et al. Protecting the health of the working age population and their families as lockdown reduces. Public Health Scotland, 2020. https:/publichealthscotland.scot/media/2686/protecting-future-working-populations-phs-social-mitigation.pdf

36 Bambra C, Riordan R, Ford J, Matthews F. The COVID-19 pandemic and health inequalities. J Epidemiol Community Health 2020;74:964-8.pmid: 32535550

37 Shipton D, Sarica S, Craig N, etal. Knowing the goal: an inclusive economy that can address the public health challenges of our time. J Epidemiol Community Health 2021;75:1129-32. . doi: 10.1136/jech-2020-216070 pmid: 34158408

38 Wellbeing Economy Alliance. Wellbeing Economy governments. 2021. https://weall.org/wego

39 Chrysopoulou A, Anielski A, Weatherhead M. Failure demand. Counting the true costs of an unjust and unsustainable economic system. Wellbeing Economy Alliance, 2021. https://weall.org/failuredemand

40 McCartney G, Fenton L, Morris G, Mackie P. ‘Superpolicies' and 'policy-omnishambles'. Public Health in Practice 2020;1:100003doi: 10.1016/j.puhip.2020.100003

This is an Open Access article distributed in accordance with the Creative Commons Attribution Non Commercial (CC BY-NC 4.0) license, which permits others to distribute, remix, adapt, build upon this work non-commercially, and license their derivative works on different terms, provided the original work is properly cited and the use is non-commercial. See: http://creativecommons.org/licenses/bync/4.0/. 